\title{
Teknik penerjemahan ungkapan sindiran pada subtitle serial televisi netflix: Bridgerton
}

\author{
Dwita Darmawati ${ }^{1}$, Sajarwa ${ }^{2}$ \\ Magister Linguistik Universitas Gadjah Mada \\ Correspondence : Dwitadarmaaa@mail.ugm.ac.id
}

\begin{abstract}
This article is a descriptive qualitative study. The aims of this study are to identify types of satirical expression and identify the translation techniques used to translate the satirical expression found in serial television subtitle entitled 'Bridgerton'. The utterance contains satirical expression found in 5 episodes of the serial television used as data in this research-the data obtained through content analysis. There are four types of satirical expression analyzed in this research; irony, satire, cynicism and sarcasm. Furthermore, the result suggests that there are 66 data of satire, 49 data of cynicism, 29 data of sarcasm, and 27 data of irony. On the other hand, there are 13 translation techniques applied in translating the utterance of satirical expression. The most dominant technique used is reduction (29) followed by discursive creation (23), established equivalent (23), literal translation (22), compensation (21), linguistic compression (20), transposition (14), modulation (8), linguistic amplification (4), borrowing (3), particularization (2), adaptation (1), dan substitution (1). The use of reduction technique is to shorten the subtitles that appear on the screen.
\end{abstract}

Keywords: satirical expression, translation techniques, subtitle, serial television.

\section{Pendahuluan}

Sindiran adalah gaya bahasa berupa ejekan yang digunakan bertujuan untuk menyinggung atau menghina mitra tutur. Menurut Keraf (2007: 143), gaya bahasa sindiran adalah bentuk gaya bahasa yang rangkaian kata-katanya berlainan dari apa yang dimaksudkan. Gaya sindiran ini meliputi: melosis, sinisme, ironi, innuendo, antifrasis, sarkasme, dan satire. Pada buku "Diksi dan Gaya Bahasa”, Keraf mendefinisikan Ironi adalah gaya bahasa yang berupa sindiran halus berupa pernyataan yang maknanya bertentangan dengan makna sebenarnya. Sementara, satire adalah gaya bahasa yang berbentuk penolakan dan mengandung kritikan dengan maksud agar sesuatu yang salah dengan 
menggunakan kata-kata yang berlawanan dalam frase atau kalimat yang sama. Sinisme adalah suatu sindiran yang mengandung ejekan serta pengungkapannya lebih kasar. Sedangkan sarkasme adalah penggunaan kata-kata yang keras dan kasar untuk menyindir atau mengeritik yang mana sindiran ini paling kasar disbanding sindiran lainnya. Penggunaan ungkapan sindiran bertujuan agar mitra tutur secara tidak langsung tersinggung atau terluka setelah memahami maksud tuturan. Hal ini karena ungkapan sindiran umumnya mengandung makna terselubung atau bahkan makna yang berlawanan dengan apa yang diucapkan. Ungkapan sindiran tak hanya terjadi dalam percakapan di kehidupan nyata melainkan juga pada film atau serial TV.

Penggunaan sindiran dalam serial TV untuk memberikan efek stilistika karena serial TV merupakan media hiburan yang diminati saat ini. Serial TV adalah program hiburan yang menayangkan mengenai kehidupan tokoh dengan latar waktu dan tempat yang variatif. Program ini juga sering kali dijadikan media untuk memahami budaya asalnya. Keunikan alur cerita mampu menarik minat penonton mancanegara. Namun, penonton terkadang kesulitan untuk memahami bahasa asing yang digunakan serta konteks budaya yang ada dalam serial TV tertentu. Sebagaimana Zojer (dalam Yuda, 2020) menyatakan bahwa selain aspek linguistik dari kedua bahasa yang diterjemahkannya, penerjemah juga harus fokus pada konteks budaya dari kedua bahasa tersebut. Oleh karena itu, diperlukan penerjemahan Audio Visual yang dapat berupa subtitle (teks) untuk memahami alur cerita dan konteks situasi dengan baik.

Subtitle adalah baris-baris teks terjemahan yang kemunculannya disesuaikan dengan waktu tuturan tokoh. Umumnya, subtitle muncul pada bagian bawah layar dengan ketentuan 30-35 huruf dalam satu baris serta durasi yang tidak boleh lebih dari 7 detik. Selain aspek linguistik, makna dan pesan, penerjemah juga harus mempertimbangkan konteks budaya baik pada Tsu maupun Tsa. Maka penerjemah harus mencari padanan terjemahan guna mematuhi norma sosial budaya di Tsa. Dengan demikian penerjemah dapat menentukan padanan yang hampir sama atau lumrah pada bahasa sasaran. Ini didukung oleh pernyataan Venuti (2012: 19) bahwa penerjemahan merupakan komunikasi antara bahasa sumber (BSu) dengan bahasa sasaran (BSa) melalui interpretasi penerjemah mengikuti sosial budaya dimana teks terjemahan tersebut dihasilkan. Dalam hal ini teknik penerjemahan dapat digunakan untuk membandingkan bahasa sumber dan bahasa sasaran.

Teknik penerjemahan adalah cara yang digunakan untuk menganalisis dan mengklasifikasi bagaimana teks terjemahan bisa menjadi sepadan dengan teks sumbernya, diterapkan pada tataran kata, frasa, klausa maupun kalimat. Adapun karakteristik teknik penerjemahan yang dipaparkan oleh Molina dan Albir (2002) adalah 1) berpengaruh terhadap hasil terjemahan, 2) klasifikasi diperoleh dengan membandingkan BSu dengan BSa, 3) berpengaruh terhadap satuansatuan teks terkecil, misalnya kata, frase, dan kalimat, 4) bersifat diskursif (logis) 
alamiah dan kontekstual, 5) bersifat fungsional. Dengan adanya perbedaan budaya dan bahasa, penerjemah berusaha untuk menentukan teknik penerjemahan yang tepat agar dapat menyampaikan makna dengan baik dan tepat sesuai dengan ketentuan-ketentuan yang ada. Ketepatan penerjemah dalam memilih teknik penerjemahan akan memengaruhi hasil terjemahan yang mana akan terjadi pergeseran pada bahasa sasaran apabila teknik yang dipilih tidak tepat.

Beberapa peneliti telah melakukan penelitian mengenai ungkapan sindiran di antaranya mengenai kualitas terjemahan ungkapan sarkasme dalam buku "The Subtle Art of Not Giving A Fuck" oleh Zawawi dan Maghfiroh (2020). Kemudian, Septiantya (2016) meneliti bentuk, makna dan tujuan tuturan sarkasme pada serial TV. Selanjutnya, Liani (2020) melakukan penelitian mengenai strategi penerjemahan ujaran sarkasme. Beberapa penelitian tersebut hanya mengangkat satu ungkapan sindiran sebagai topik penelitian, yaitu sarkasme. Terlebih, belum adanya pembahasan mengenai teknik penerjemahan pada penelitian-penelitian tersebut Sehingga, peneliti menemukan celah untuk meneliti beberapa ungkapan sindiran selain sarkasme serta penerapan teknik penerjemahan oleh penerjemah subtitle.

Salah satu serial TV yang mengakomodasi ungkapan sindiran adalah serial TV Bridgerton. Serial TV yang rilis pada 25 desember 2020 di Netflix ini mendapatkan rating $89 \%$ dari Rotten Tomatoes yang merupakan movies rater. Berasal dari Britania Raya, Bridgerton cukup diminati oleh penonton mancanegara, termasuk Indonesia. Serial TV ini bercerita tentang masyarakat London kelas atas pada tahun $1800 a n$. Pada tahun tersebut tata krama dan sopan santun sangat berpengaruh terhadap nama baik keluarga besar. Dengan genre romance dan historical film, fokus cerita ada pada perjalanan hidup tokoh bernama Daphne Bridgerton dalam mencari pasangan hidup. Meski demikian tak jarang ditemui konflik. Serial TV ini menarik untuk diteliti karena adanya unsur budaya yang kental serta penggunaan unsur linguistik dalam ungkapan sindiran yang jauh berbeda dengan zaman sekarang.

Penelitian ini bertujuan untuk mengetahui ungkapan sindiran yang digunakan serta kategori jenis sindiran. Penelitian ini mengidentifikasi 4 jenis sindiran yaitu sinisme, ironi, satire dan sarkasme. Selanjutnya, peneliti juga mengidentifikasi teknik penerjemahan yang digunakan dalam menerjemahkan ekspresi sindiran yang ditemukan dengan menggunakan teori teknik penerjemahan Molina dan Albir (2002).

\section{Metode}

Penelitian ini merupakan penelitian deskriptif kualitatif karena penelitian ini bertujuan untuk mendeskripsikan teknik penerjemahan yang digunakan oleh penerjemah subtitle. Sebagaimana Sutopo dan Moleong (dalam Dinari, 2017) yang menyatakan bahwa karakteristik penelitian deskriptif kualitatif yaitu data 
yang dikumpulkan terutama berupa kata-kata, kalimat, gambar, yang memiliki arti lebih daripada sekedar angka atau frekuensi. Data dalam penelitian ini adalah semua frasa, klausa atau kalimat yang mengandung ungkapan sindiran yang berjumlah 171 data. Sumber data berupa serial TV Bridgerton episode satu hingga lima beserta subtitle dari bahasa Inggris ke bahasa Indonesia yang rilis pada tahun 2020 di platform Netflix.

Partisipan dalam penelitian ini adalah semua tokoh dalam serial TV Bridgerton yang melakukan tuturan mengandung ungkapan sindiran. Ungkapan sindiran tersebut diperoleh melalui analisis isi. Peneliti menonton serial TV Bridgerton menggunakan subtitle bahasa Inggris dan bahasa Indonesia dengan seksama. Klasifikasi sindiran menggunakan teori oleh Keraf yang meliputi: sinisme, ironi, sarkasme, dan satire. Kemudian, mencatat dan mengklasifikasikan frasa, klausa atau kalimat yang mengandung ungkapan sindiran. Untuk menentukan perbedaan jenis sindiran peneliti mengamati konteks percakapan serta unsur linguistik yang digunakan.

Seluruh data yang dikumpulkan dianalisis menggunakan teknik terjemahan menurut Molina dan Albir (2002). Pemerolehan teknik dilakukan dengan cara membandingkan subtitle bahasa sumber dan bahasa sasaran sehingga didapatkan sejumlah teknik terjemahan yang digunakan penerjemah dalam menerjemahkan ungkapan sindiran yang ada dalam serial TV tersebut.

\section{Hasil dan pembahasan}

Di dalam penelitian ini ditemukan 171 ungkapan sindiran pada subtitle serial TV Bridgerton yang terdiri atas satire sebanyak 66 ungkapan, sinisme sebanyak 49 ungkapan, sarkasme sebanyak 29 ungkapan, dan ironi sebanyak 27 ungkapan.

Tabel 1. Distribusi Kemunculan Ungkapan Sindiran di Subtitle Bridgerton

\begin{tabular}{ccc}
\hline No. & Jenis Sindiran & Jumlah \\
\hline 1. & Satire & 66 \\
\hline 2. & Sinisme & 49 \\
\hline 3. & Sarkasme & 29 \\
\hline 4. & Ironi & 27 \\
\hline & Total & 171 \\
\hline
\end{tabular}

Kemudian, 171 data dianalisis untuk mengetahui teknik penerjemahan yang digunakan oleh penerjemah subtitle. Diketahui bahwa terdapat 13 teknik penerjemahan berdasarkan teori yang dikemukakan oleh Molina dan Albir (2002). Teknik yang digunakan oleh penerjemah untuk menerjemahkan subtitle serial TV Bridgerton, yaitu: reduksi, kreasi diskursif, padanan lazim, penerjemahan harfiah, kompensasi, kompresi linguistik, transposition, modulasi, amplifikasi linguistik, peminjaman, partikularisasi, adaptasi, dan 
substitusi. Tabel distribusi penggunaan teknik-teknik tersebut adalah sebagai berikut.

Table 2. Distribusi Teknik Penerjemahan dalam subtitle serial TV Bridgerton

\begin{tabular}{rccc}
\hline No. & Teknik Penerjemahan & Jumlah & Persentase (\%) \\
\hline 1. & Reduksi & 29 & 16,95 \\
\hline 2. & Kreasi Diskursif & 23 & 13,45 \\
\hline 3. & Padanan Lazim & 23 & 13,45 \\
\hline 4. & Penerjemahan Harfiah & 22 & 12,86 \\
\hline 5. & Kompensasi & 21 & 12,28 \\
\hline 6. & Kompresi Linguistik & 20 & 11,69 \\
\hline 7. & Transposisi & 14 & 8,18 \\
\hline 8. & Modulasi & 8 & 4,67 \\
\hline 9. & Amplifikasi Linguistik & 4 & 2,33 \\
\hline 10. & Peminjaman & 3 & 1,75 \\
\hline 11. & Partikularisasi & 2 & 1,16 \\
\hline 12. & Adaptasi & 1 & 0,58 \\
\hline 13. & Substitusi & 1 & 0,58 \\
\hline
\end{tabular}

\section{Reduksi}

Teknik reduksi adalah teknik penerjemahan dengan frekuensi tertinggi sebanyak 29 data. Menurut Molina \& Albir (2002), teknik ini termasuk dalam kategori teknik pengurangan yang mana informasi dari teks sumber dipadatkan tanpa mengurangi makna yang ada. Contoh penerapan teknik reduksi pada ungkapan sindiran sebagai berikut:

(1) Tsu: Should it have anything to do with the unpaid balance you left on ourbetting books winter last?

Tsa: Adakah hubungannya dengan utang taruhanmu musim dingin lalu?

Konteks percapakan ungkapan sinisme pada data (1) ketika Lord Ambrose yang berusaha untuk mendekati Dephnie, namun sang kakak, Anthony menginterupsi perkenalan mereka karena Lord Ambrose memiliki utang di klub. Sehingga, dia tidak ingin adik kesayangannya didekati oleh seorang penghutang. Klausa 'the unpaid balance you left on our betting books' dipadatkan menjadi 'utang taruhanmu' tanpa mengubah makna yang disampaikan pada teks sumber 
walau ada beberapa informasi yang dikurangi. Pemadatan informasi tersebut dilakukan agar subtitle yang tampil menjadi lebih ringkas.

(2) Tsu: Why is he not saying anything? He is four years old. He should be able to speak.

Tsa: Kenapa dia tak bicara? Usianya empat tahun. Seharusnya bisa

Percakapan data (2) merupakan cuplikan kilas balik masa kecil Simon saat ia gagap bicara. Kalimat tersebut dilontarkan oleh ayah Simon ketika ia tau Simon tidak bisa berbicara dengan lancar. Frasa 'tak bicara' sebagai padanan makna yang lebih singkat dari klausa 'not saying anything'. Sedangkan, frasa 'seharusnya bisa' adalah hasil pemadatan dari klausa 'he should be able to speak'. Peringkasan informasi demikian bertujuan agar tidak bertele-tele sehingga penonton dapat memahami percakapan. Contoh data ini berupa kritik sehingga dikategorikan sebagai satire.

\section{Kreasi diskursif}

Kreasi diskursif adalah teknik dengan menggunakan padanan sementara untuk menerjemahkan istilah yang tidak terduga atau di luar konteks pada teks sasaran. Ditemukan 23 data yang menerapkan teknik ini. Beberapa data tersebut adalah sebagai berikut:

(3) Tsu: Someone must guard my poor sister from the bucks and pinks.

Tsa: Ada yang harus jaga adik malangku dari pria muda payah.

Penggunaan teknik kreasi diskursif ditemukan pada data (3) yang merupakan sinisme. Frasa 'the bucks and pinks' adalah istilah lama bahasa sumber yang memiliki arti 'pria modis namun berperilaku menyimpang seperti pecandu alkohol, obat-obatan dan seks'. Penerjemah menggunakan frasa sementara 'pria muda payah' sebagai padanan makna. Konteks situasi, saat Anthony pamit pergi kepada Sierra karena harus mendampingi adiknya ke acara pesta. Acara pesta tersebut menjadi ajang mencari jodoh, sehingga Anthony tidak ingin adiknya mendapatkan pasangan yang buruk.

(4) Tsu: A bastard he sent away before the miss even popped? Tsa: Anak haram yang dia usir sebelum dilahirkan?

Konteks kalimat tanya (4) ketika para pelayan sedang menyebarkan gosip dari mulut ke mulut mengenai perilaku tercela seorang Baron bernama Lord Berbrooke yang telah menghamili seorang pelayan di rumahnya dan tidak menafkahi, bahkan mengusir pelayan tersebut ke desa. Frasa 'dilahirkan' menjadi padanan sementara 'the miss even popped'. Secara literal, frasa tersebut bermakna 'nona bahkan meletuskan', namun pernyataan tersebut 
membingungkan sehingga jika dilihat dari konteks pembicaraan dapat diartikan sebagai 'dilahirkan'. Penggunaan teknik ini tidak mengubah makna walau struktur berbeda. Kalimat tanya tersebut juga termasuk sinisme yang mana penggunaan kata 'a bastard' dianggap kasar.

\section{Padanan lazim}

Teknik padanan lazim adalah penggunaan istilah atau ekspresi yang lazim sebagai padanan pada teks sasaran. Ada 23 data yang menggunakan padanan lazim dalam mengalihbahasakan ungkapan sindiran, contoh sebagai berikut:

(5) Tsu: Your mother would weep to know her dearest friend was a stranger to her son.

Tsa: Ibumu akan menangis jika tahu sahabatnya tampak asing bagi putranya.

(6) Tsu: The only thing we are devoted to is putting food in our children's mouths. Tsa: Kami hanya peduli soal memberi makan anak-anak kami.

Kedua contoh data menunjukkan penggunaan istilah lazim yang telah disesuaikan pada bahasa sasaran. Secara harfiah, frasa 'dearest friend' bermakna 'teman tersayang'. Pada bahasa sasaran terdapat ungkapan setara yaitu 'sahabat'. Begitu pula dengan contoh kedua yang menggunakan padanan 'memberi makan anak-anak kami'. Penerjemah berusaha untuk mempertimbangkan padanan lazim pada bahasa sasaran. Contoh (5) merupakan ironi karena orang yang dimaksud telah meninggal sehingga berkebalikan dengan apa yang diucapkan. Sedangkan, contoh data (6) merupakan satire yang diucapkan oleh istri seorang petinju yang tidak peduli mengenai hal yang tidak berkaitan dengan keluarganya.

\section{Penerjemahan harfiah}

Teknik penerjemahan harfiah adalah mengalihbahasakan teks sumber ke teks sasaran dengan cara menerjemahkan kata demi kata. Terdapat 22 data ditemukan menggunakan penerjemahan harfiah. Berikut contoh datanya.

(7) Tsu: You appear displeased.

Tsa: Kau tampak tak senang.

(8) Tsu: You diabolical

Tsa: Kau kejam

Konteks percapakan (7) terjadi ketika Simon diundang makan malam bersama di kediaman Vicount Bridgerton namun Daphne, anak ke empat dari keluarga tersebut terlihat kesal harus duduk di samping Simon. Sindiran 'you appear displeased' diucapkan oleh Simon kepada Daphne. Sedangkan, sindiran 'you diabolical' dilontarkan oleh Benedict yang menganggap Lady Danbury kejam karena membiarkannya mengkritik lukisan Lord Grenvile. Sang pelukis berdiri 
di samping Lady Danbury akan tetapi Benedict tidak mengetahuinya karena terhalang badan Lady Danbury. Contoh (7) dan (8) yang merupakan satire dan sarkasme diterjemahkan kata demi kata secara harfiah, tanpa menyesuaikan dengan konteks walau demikian pesan dari teks sumber dapat disampaikan dengan baik.

\section{Kompensasi}

Kompensasi adalah teknik yang mengganti suatu informasi atau efek stilistika karena terdapat elemen sepadan pada teks sasaran. Ada 21 data yang mengaplikasikan teknik kompensasi. Adapun contoh pengaplikasiannya adalah sebagai berikut.

(9) Tsu: She's only been readying herself the entire night

Tsa: Dia baru siapkan diri semalaman

Konteks ungkapan sindiran (9) oleh Eloise ditujukan kepada Daphne yang terlalu lama mempersiapkan diri ketika mereka akan pergi menghadiri acara penting di kerajaan. Frasa 'the entire night' yang bermakna harfiah 'sepanjang malam' diubah menjadi 'semalaman' untuk mengungkapkan bahwa Daphne sangat mempersiapkan diri bahkan dari malam sebelumnya. Sindiran ini merupakan ironi karena berkebalikan dengan fakta bahwa Daphne mempersiapkan diri dari pagi hari.

(10) Tsu: Now, this is far too grim a mood for the celebration I was counting on. Tsa: Suasana saat ini terlalu suram untuk perayaan yang kuharapkan.

Ungkapan sindiran (10) yang termasuk satire ini diucapkan oleh Lady Danbury kepada Daphne, Simon dan Anthony yang terlihat murung padahal seharusnya mereka berbahagia karena Daphne dan Simon akan segera menikah. Jika 'I was counting on' diterjemahkan secara harfiah menjadi 'aku menghitung pada'. Klausa tersebut dialihbahasakan menjadi 'kuharapkan' agar hasil terjemahan terasa alamiah dan lebih mudah dimengerti oleh penonton. Elemen pada bahasa diubah tanpa mengubah efek stilistika.

\section{Kompresi linguistik}

Teknik selanjutnya, kompresi linguistik dikategorikan ke dalam teknik penerjemahan pengurangan. Teknik yang memadatkan informasi dengan penyatuan elemen-elemen linguistik ini diaplikasikan pada 20 ungkapan sindiran. Berikut contoh datanya

(11) Tsu: Do not tell me that is yet another scandal sheet.

Tsa: Jangan bilang itu kertas skandal. 
Pengurangan elemen linguistik pada hasil terjemahan 'that is yet another scandal sheet' menjadi 'itu kertas skandal' bertujuan untuk memadatkan elemen pada bahasa sasaran. Pengunaan teknik kompresi linguistik bertujuan agar subtitle menjadi lebih ringkas tanpa mengurangi pesan yang ingin disampaikan. Konteks situasi terjadi saat Violet yang memarahi salah satu anaknya sedang membaca koran Lady Whistledown yang berisi gosip para elite Governor Square. Tuturan tersebut dikategorikan sebagai sinisme karena penggunaan 'scandal' yang memberi kesan kasar.

(12) Tsu: She's rather dowdy, is she not?

Tsa: Dia agak lusuh, bukan?

Contoh 'is she not' dialihbahasakan menjadi 'bukan' dengan mengurangi elemen linguistik. Kata 'bukan' telah mencakup makna yang ingin disampaikan teks sumber. Teknik ini berbeda dengan reduksi yang mana sebagian informasi atau pesan yang ingin disampaikan hilang sebagian. Sedangkan, teknik ini hanya mengurangi unsur linguistik. Konteks percakapan yang temasuk sinisme ini adalah saat Lady Featherington meminta pendapat temannya tentang sepupu suaminya bernama Miss Thompson yang berasal dari desa.

\section{Transposisi}

Teknik transposisi digunakan untuk mengubah kategori gramatikal seperti mengganti nomina menjadi verba pada teks sasaran atau mengganti kata menjadi frasa. Ditemukan 14 data yang menerapkan teknik ini. Contoh data yang ditemukan sebagai berikut.

(13) Tsu: What a suspicious illness you came down with.

Tsa: Penyakitmu sungguh mencurigakan.

Konteks situasi contoh (13), saat Colin yang sudah lama tidak berjumpa dengan Marina karena ia sakit. Terdapat perubahan kategori gramatikal dari adjektiva menjadi verba. Kata 'suspicious' pada teks sumber merupakan kata adjektiva yang dialihbahasakan menjadi verba 'mencurigakan' pada teks sasaran.

(14) Tsu: I could have until Judgement Day and still not manage a smile for that wretched fate.

Tsa: Sampai kiamat pun, aku tak akan bisa tersenyum atas nasib buruk itu.

Sementara, pada contoh (14) kata 'a smile' yang merupakan nomina berubah menjadi verba 'tersenyum'. Hal ini menunjukkan perubahan kategori gramatikal dari nomina menjadi verba. Pernyataan tersebut dituturkan oleh Marina karena dipaksa untuk bersikap baik kepada calon suami pilihan Lady 
Featherington. Contoh data (13) dan (14) merupakan sinisme yang jika dilihat dari konteks maupun unsur linguistik, penuturan keduanya tergolong kasar.

\section{Modulasi}

Modulasi adalah teknik penerjemahan yang mengganti sudut pandang, fokus atau kategori kognitif teks sumber dengan leksikal atau struktur yang berbeda. Ditemukan 8 data yang menggunakan teknik modulasi. Contoh data sebagai berikut.

(15) Tsu: His first and only, I believe.

Tsa: Pasti yang pertama dan satu-satunya.

(16) Tsu: I cannot imagine a greater show of disrespect than promising me to Nigel Berbrooke

Tsa: Tak terbayangkan penghinaan yang lebih besar daripada menjanjikanku ke Nigel Berbrooke

Teknik penerjemahan modulasi ditemukan pada ungkapan sindiran satire pada data (15) dan sinisme pada data (16). Kedua kalimat tersebut mengubah sudut pandang dengan mempertahankan makna yang sama dengan teks sumber. Pada data (15) perubahan 'I believe' menjadi 'pasti' yang memberikan penekanan pada frasa setelahnya. Sementara data (16), frasa 'I cannot imagine' diubah sudut pandangnya dengan menghapus subjek 'I' sehingga menjadi 'tak terbayangkan'. Kalimat yang semula pasif berubah menjadi aktif karena perubahan sudut pandang ini. Data (15) merupakan satire yang mana pernyataan tersebut berupa kritikan yang diberikan Anthony kepada Lord Ambrose. Sementara, penggunaan kata 'penghinaan' menjadikan data (16) masuk ke dalam kategori sinisme. Pernyataan tersebut diberikan kepada Anthony oleh Daphne yang tidak terima karena ingin dijodohkan dengan Nigel.

\section{Amplifikasi linguistik}

Teknik lainnya yang diaplikasikan penerjemah pada 4 data adalah amplifikasi linguistik dengan menambahkan elemen linguistik dalam teks terjemahan. Penerapan teknik dapat dilihat dari contoh:

(17) Tsu: You are a rake

Tsa: Kau benar-benar amoral.

Ungkapan sindiran (17) dituturkan oleh Daphne merupakan sarkasme untuk menyindir Simon Ketika mereka sedang makan malam bersama. Penambahan elemen linguistik berupa 'benar-benar' bertujuan untuk memberikan penekanan pada sindiran tersebut.

(18) Tsu: The hound deserved better. 
Tsa: Anjingnya layak dapat yang lebik baik.

Dari data (18) terdapat penambahan berupa 'dapat yang' pada teks sasaran. Secara harfiah, kata 'layak' sudah cukup untuk mewakili kata 'deserved'. Hal ini menunjukkan bahwa penerjemah ingin memberikan penjelasan lebih detail pada ungkapan tersebut sehingga terdengar lebih alamiah. Tuturan tersebut termasuk jenis sindiran ironi karena anjing yang dimaksud terdapat dalam sebuah lukisan.

\section{Peminjaman}

Teknik peminjaman diaplikasikan pada 3 data dengan mengambil secara langsung kata atau ekspresi dari bahasa sumber. Berikut contoh data penggunaannya.

(19) Tsu: Lady Whistledown finds "banality"

Tsa: Lady Whistledown pikir itu "dangkal"

(20) Tsu: For her powerful right hook?

Tsa: Karena hook kanan yang kuat?

Ungkapan (19) dan (20) merupakan sindiran satire yang mana berupa kritik. Pada contoh data (19) teknik peminjaman diterapkan pada nama tokoh 'Lady Whistledown' yang diambil secara langsung tanpa ada penyesuaian. Padahal pada bahasa sasaran kata 'Lady' dapat diterjemahkan menjadi 'nyonya' akan tetapi penerjemah ingin mempertahankan penamaan tokoh yang asli dari serial TV Bridgerton. Sedangkan data (20) menerapkan teknik peminjaman pada noun 'hook' yang diambil tanpa pengubahan. Terdapat kemungkinan bahwa penerjemah mengalami kesulitan untuk mencari padanan kata yang maknanya sesuai dengan konteks. Konteks ungkapan data (20) adalah ketika Simon menyindir mata Lord Berbrooke yang lebam akibat tinjuan dari Daphne. Tinjuan itu adalah upaya untuk membela dirinya yang ingin dilecehkan Lord Berbrooke. Simon menjadi saksi peristiwa tersebut.

\section{Partikularisasi}

Partikularisasi adalah teknik yang menerjemahkan istilah yang lebih konkrit dalam teks sasaran. Penerapan teknik ini ditemukan pada 2 data, sebagai berikut.

(21) Tsu: The London season is already terribly monotonous as it is. Must your wardrobe do the same?

Tsa: Musim di London sudah sangat monoton. Haruskah busanamu juga begitu?

Konteks ungkapan sindiran data (21) ketika Lady Danbury mengomentari pakaian Simon karena ia terlihat memakai pakaian dengan warna yang hampir 
sama setiap hari. Dengan demikian, ujaran tersebut termasuk jenis sindiran satire. Frasa 'your wardrobe' secara harfiah pada bahasa sasaran bermakna 'lemari pakaian' dapat juga diartikan sebagai 'koleksi pakaianmu'. Penerjemah menggunakan padanan kata yang lebih spesifik agar sesuai dengan konteks yakni menggunakan kata 'busanamu'.

(22) Tsu: I am perfectly well, no thanks to you idiots.

Tsa: Aku baik-baik saja, bukan berkat kalian, pria-pria bodoh.

Pada contoh (22), ungkapan terjadi saat Daphne berusaha untuk menghentikan Simon dan Anthony yang sedang duel. Akibat terkejut mendengar suara tembakan, Daphne jatuh dari kudanya dan tersungkur ke tanah, kemudian para pria menanyakan keadaannya. Kata 'idiots' ditujukan kepada Simon dan Anthony karena kesal dengan apa yang kedua pria tersebut lakukan. Penerjemah menggunakan padanan kata yang detail 'pria-pria bodoh' untuk memperjelas kepada siapa sindiran tersebut ditujukan. Walau demikian, makna yang ingin disampaikan dari teks sumber tidak berubah. Data ini termasuk jenis sindiran sarkasme karena kata 'idiots' termasuk celaan.

\section{Adaptasi}

Adaptasi adalah teknik yang menggunakan elemen budaya yang lebih diketahui pada bahasa sasaran sebagai padanan. Teknik ini hanya diterapkan pada 1 data berikut.

(23) Tsu: Three misses foisted upon the marriage market like sorrowful sows by their tasteless tactless mama.

Tsa: Tiga orang gadis dipaksa masuk bursa perjodohan bagai babi yang sedih oleh ibu mereka yang bodoh dan tak bijak.

Frasa 'marriage market' pada data (23) mengalami penyesuaian dengan istilah budaya pada bahasa sasaran menjadi 'bursa perjodohan'. Hasil terjemahan tersebut digunakan karena lebih lumrah dibandingkan dengan terjemahan harfiahnya 'pernikahan pasar'. Konteks situasi ungkapan sindiran sinisme ini dituturkan oleh Lady Whistledown selaku narator dari cerita yang ada di serial TV Bridgerton.

\section{Substitusi}

Teknik terakhir yang ditemukan hanya pada 1 data adalah teknik substitusi. Teknik yang menggunakan paralinguistik (isyarat dan intonasi) sebagai pengganti elemen-elemen linguistik. Datanya adalah sebagai berikut.

(24) Tsu: That one is a terrible gossip.

Tsa: Dia penggosip yang buruk. 
Pada contoh data (24) yang merupakan sindiran sinisme, pengubahan unsur substitusi terdapat pada frasa 'that one' yang dialihbahasakan menjadi 'dia'. Frasa tersebut merupakan sebuah isyarat yang digunakan oleh The Queen dengan menatap ke arah pelayannya bernama Brimsey. Hal ini adalah penyesuaian dengan isyarat untuk menghindari menyebut nama pelayan tersebut.

\section{Kesimpulan}

Dalam penelitian ini, analisis ungkapan sindiran mengungkapkan bahwa terdapat 171 data yang ditemukan pada subtitle serial TV Bridgerton. Terdapat 66 data ungkapan sindiran satire, 49 data ungkapan sindiran sinisme, 29 data ungkapan sindiran sarkasme and 27 data ungkapan sindiran ironi. Subtitle diterjemahkan ke dalam teks sasaran dengan mengaplikasikan 13 teknik penerjemahan, reduksi, kreasi diskursif, padanan lazim, penerjemahan harfiah, kompensasi, kompresi linguistik, transposition, modulasi, amplifikasi linguistik, peminjaman, partikularisasi, adaptasi, dan substitusi. Teknik reduksi adalah teknik yang dominan digunakan karena pada penerjemahan Audio Visual terdapat ketentuan mengenai baris dan banyaknya karakter. Sehingga, teknik ini diterapkan untuk meringkas subtitle yang muncul. Teknik ini cocok digunakan untuk menerjemahkan subtitle. Pengaplikasian teknik penerjemahan tidak memengaruhi makna sesungguhnya teks sumber. Hasil terjemahan berorientasi pada teks sasaran yang mana teks disesuaikan dengan budaya dan kamus bahasa sasaran.

\section{Daftar pustaka}

Dinari, Irene., M.R. Nababan, dan Djatmika. (2017). The analysis of translation techniques of irony and sarcasm in novel entitled The Return of Sherlock Holmes and the effects on translation. Prasasti: Journal of Linguistics, 2 (1), 6988.

Keraf, Gorys. (2007). Diksi dan Gaya Bahasa. Jakarta: Gramedia.

Liani, Ghustiva. (2020). Strategi Penerjemahan Ujaran Sarkasme Beserta Orientasinya dalam Tiga Film Karya Sacha Baron Cohen. Tesis. Yogyakarta: Fakultas Ilmu Budaya, Universitas Gadjah Mada.

Molina, L., \& Hurtado Albir, A. (2002). Translation Techniques Revisited: A Dynamic and Functionalist Approach. Meta: Journal Des Traducteurs, 47(4), 498.

Septiantya, Alva. (2016). Bentuk, makna dan tujuan Sarkasme pada serial TV 
"House MD" episode 1-5 musim 1. Tesis. Yogyakarta: Fakultas Ilmu Budaya, Universitas Gadjah Mada.

Venuti, Lawrence. (2012). The Translation Studies Reader (third edition). London and New York: Routledge.

Yuda, Jotika Purnama., Nababan, Mangatur., dan Djatmika. (2020). Teknik Penerjemahan Peristiwa Tutur Bertengkar Dalam Subtitle Film Ted 2. Aksara, 32 (1), 151-166.

Zawawi. Moh., dan Maghfiroh, Devi Laila. (2020). Sarcasm and The Translation Qualityin The Subtle Art of Not Giving A Fuck Book. LiNGUA, 15 (2), 253260. 